\title{
Measuring the Multidimensional Construct of Pornography: A Long and Short Version of the Pornography Usage Measure
}

\author{
Dean M. Busby \\ Brigham Young University - Provo, dean_busby@byu.edu \\ Brian J. Willoughby \\ Brigham Young University - Provo \\ Hsin-Yao Chiu \\ Brigham Young University - Provo \\ Joseph A. Olsen \\ Brigham Young University - Provo \\ Follow this and additional works at: https://scholarsarchive.byu.edu/facpub \\ Part of the Other Social and Behavioral Sciences Commons
}

\section{Original Publication Citation}

Busby, D. M., Willoughby, B. J., Chiu, H-Y., Olsen, J. A. (2020). Measuring the multidimensional construct of pornography: A long and short version of the Pornography Usage Measure.

Archives of Sexual Behavior.

\section{BYU ScholarsArchive Citation}

Busby, Dean M.; Willoughby, Brian J.; Chiu, Hsin-Yao; and Olsen, Joseph A., "Measuring the Multidimensional Construct of Pornography: A Long and Short Version of the Pornography Usage Measure" (2020). Faculty Publications. 4644.

https://scholarsarchive.byu.edu/facpub/4644

This Peer-Reviewed Article is brought to you for free and open access by BYU ScholarsArchive. It has been accepted for inclusion in Faculty Publications by an authorized administrator of BYU ScholarsArchive. For more information, please contact ellen_amatangelo@byu.edu. 


\title{
Measuring the Multidimensional Construct of Pornography: A Long and Short Version of the Pornography Usage Measure
}

\author{
Dean M. Busby ${ }^{1} \cdot$ Brian J. Willoughby ${ }^{1} \cdot$ Hsin-Yao Chiu ${ }^{1} \cdot$ Joseph A. Olsen ${ }^{1}$
}

Received: 8 June 2018 / Revised: 18 March 2020 / Accepted: 20 March 2020 / Published online: 2 April 2020

(c) Springer Science+Business Media, LLC, part of Springer Nature 2020

\begin{abstract}
With the increase in the availability and usage of pornography, the research on the effects of pornography has also increased. This research has uncovered several controversies in the field regarding how pornography usage influences attitudes, sexual behaviors, and relationships. However, many of the measures of pornography are problematic as there is often little reliability and validity information for them and it is not clear that participants in these research studies are referring to the same types of materials when they answer pornography usage questions. Consequently, many of the research findings are suspect and it is crucial to develop reliable and valid scales to measure general pornography usage. In this study, we present both a 20 -item and a 7-item version of the Pornography Usage Measure (PUM) that is based on extensive previous research on what types of materials individuals consider pornographic and that indicates pornography is a multidimensional construct. We evaluated the reliability and validity of both versions by using an MTurk sample of 934 males and 705 females $(N=1639$ total) to conduct confirmatory factor analyses, item response analyses, and structural equation model analyses. These analyses demonstrated that there were adequate reliability and early evidence for content, construct, concurrent, and predictive validity for both versions of the PUM. This measure could improve the quality of future research on pornography by providing more consistency between different studies about what is being measured when individuals indicate their pornography usage patterns.
\end{abstract}

Keywords Pornography $\cdot$ Sexually explicit media $\cdot$ Bi-factor models

\section{Introduction}

Pornography use has increased dramatically in recent years, and scientific studies exploring this phenomenon have also expanded exponentially (Butler, Pereyra, Draper, Leonhardt, \& Skinner, 2017; Grubbs, Volk, Exline, \& Pargament, 2015). One of the challenges in any relatively new area of inquiry is how to measure a construct in reliable and valid ways. The measurement of pornography has suffered from the common pitfalls of other areas in that many of the measures had little or no reliability or validity information provided, and they were often single-item measures asking respondents to estimate how often they used the undefined construct of pornography during a specific time frame (Malamuth, Addison, $\&$ Koss, 2000). While a single-item measure of simple behaviors can be sufficient, pornography is not a simple construct

Dean M. Busby

dean_busby@byu.edu

1 School of Family Life, Brigham Young University, 2086 JFSB, Provo, UT 84602, USA or behavior as there are differing views of what constitutes pornography (Willoughby \& Busby, 2016), substantial social and cultural reasons to underreport pornography (Rasmussen, Grubbs, Pargament, \& Exline, 2018), and at least some researchers have found pornography to be multidimensional (Busby, Chiu, Willoughby, \& Olsen, 2017).

While existing measures are often beset with common measurement challenges, the research that has been gathered shows that pornography use is associated with individual and relational health, and sexual attitudes and functioning (Hald, Seaman, \& Linz, 2014). In addition, some of the more recent research suggests that pornography use is becoming more frequent, ubiquitous, and likely to be associated with serious relationship challenges, including instability leading to divorce (Perry \& Schleifer, 2018; Price, Patterson, Regnerus, $\&$ Walley, 2016). This makes improving the measurement of pornography even more crucial. 


\section{Missing Content Validity for Many Existing Measures}

One of the most important issues in terms of measuring pornography is that participants have different standards as to what constitutes pornography (Willoughby \& Busby, 2016). For some people, very mild depictions of partial nudity or even just textual descriptions are considered pornographic, whereas for others something is not considered pornography unless it is a graphic video depiction of sex acts. This is particularly problematic as so much of the pornography research uses single-item measures where participants are not given definitions of pornography and are allowed to determine for themselves what they think is pornography as they answer these questions. This means that when scholars are trying to obtain estimates from participants as to how often pornography is viewed, the tendency to have different standards is a potentially lethal problem with validity as some participants may be referring to very mild types of sexual media, whereas others will be thinking about extremely graphic types of sexual media (Daneback, Traeen, \& Mansson, 2009).

To avoid these types of problems when developing new measures, scholars often try to establish a degree of content validity (Sireci \& Sukin, 2013). Researchers accomplish this by asking experts in an area to rate a set of items for how well they represent a particular construct (Fitzpatrick, 1983; Kingston, Scheuring, \& Kramer, 2013). It is crucial that respondents are generally referring to the same type of sexual media when they answer how often they have been viewing pornography, since researchers and applied professionals are going to use these instruments about pornography to assess usage from participants. Consequently, rather than having a set of "experts" to define whether an item represents a good pornography item for an instrument, it is more relevant to ask participants about how often they view specific types of sexual media that have already been established as representing what most people consider pornography. Using participants as the content experts also avoids the potential problem with using scholars as content experts as their extensive experience with pornography research may create a skewed perspective that requires the material to be much more extreme before it is considered pornographic. Recently, some researchers have explored what items representing different types of sexual media most individuals will rate as pornographic, thereby providing a foundation for building a measure that has an important type of content validity from the typical user of sexual media (Busby et al., 2017). By asking participants to determine with very specific scenarios what is pornographic or not, this provides a clear reference point and improved measurement validity. It may be possible to go one step beyond these research findings by creating a theoretically, conceptually, and statistically sound measure that uses these same scenarios, but captures participants' pornography usage. Using these scenarios has the added advantage of not asking participants the loaded question of "how often have you viewed pornography?" Instead, they are asked how often they have viewed or read, or watched sexual media similar to a specific scenario that is presented to them that has already been validated as being "pornographic," but is not labeled as such.

\section{The Multidimensional Nature of Pornography}

A second important issue regarding measurement of any construct is whether the construct is unidimensional or multidimensional (Busby et al., 2017; Hartig \& Höhler, 2008). Dimensionality has hardly been a focus of the development of Pornography Usage Measurements in the past. However, with the added current complexity of media and usage patterns involved, it is important to consider the possibility that pornography use actually represents multiple traits and dimensions at the same time. As a result, in a second study exploring factor analytic patterns with the same items individuals rated as representing pornography, Busby et al. (2017) discovered that these items were indeed multidimensional in nature, simultaneously evaluating the two dimensions of sensitization and differentiation.

Recently, several new measures for pornography have been developed (Bôthe et al., 2018: Grubbs, Sessoms, Wheeler, \& Volk, 2010; Hald \& Štulhofer, 2016). However, these measures are centered on how people feel about their pornography use (i.e., whether it is compulsive or addictive) or what general types of pornography are viewed (self-defined as to what is meant by various types such as sadomasochistic or fetish). Consequently, the researchers of these instruments entirely bypass the issue of what an individual is referring to when they answer questions about the frequency of their pornography use. This means that the arsenal of options for researchers is increasing in terms of understanding how people feel about their usage patterns, but the question of what users are referring to when they indicate how often they view pornography remains unclear. Also, as with any behavioral phenomenon, we would expect the typical person to not fall within the categories of compulsive or addictive use. This speaks to the importance of a measure for the general population that can be used to capture general pornography use.

\section{Purpose of the Study and Research Questions}

The primary purpose of this study was to create a scale to measure pornography usage that contains items that served three purposes. First, the items should be considered pornographic by most participants. This will help clear up the problem of what people are referring to when they report on 
pornography usage. Second, the items should contain material that is at least occasionally viewed by many participants as items that are considered pornographic, but never viewed will serve little value. Third, the items should capture the two dimensions of pornography previously found in the literature (Busby et al., 2017). In order to accomplish this purpose, we developed and tested an instrument of 20 items on pornography use, which we named the Pornography Usage Measure (PUM). We also evaluated and recommend a shortened version of PUM for any researcher who may not want to use the full 20-item version. As part of the research purposes, after the full and shortened versions of PUM were created and evaluated, we tested PUM by using it as an independent variable to predict an outcome variable. To summarize, we had the following research questions:

1. Is there evidence that the Pornography Usage Measure (PUM) is a reliable measure?

2. Is there evidence for concurrent validity for the PUM with other general pornography use questions?

3. Is there evidence for construct validity for the PUM in that the two dimensions identified in previous research for pornography are verifiable through multidimensional factor analyses?

4. Is there evidence for predictive validity for the PUM when being used as an independent variable predicting a general relationship outcome such as relationship stability?

5. Can a shortened version of PUM be created that would be adequate for most purposes?

\section{Method}

\section{Participants and Procedure}

Participants in this study were recruited through Amazon Mechanical Turk (MTurk, see also https://www.mturk.com). MTurk is an online platform which allows researchers to administer surveys (also known as Human Intelligence Tasks or HITs) to any participant who has Internet access and is willing to fill out the survey. Prior to filling out the survey, participants were asked to read and digitally sign a consent form that ensured they understood the nature, purposes, and risks (if any) of the study. The final sample of this study consisted of 1639 English-speaking individuals from various countries, largely consisting of the U.S. and Commonwealth Nations though the geographic data provided were not precise enough to describe specific sample sizes in each of these countries. Fifty-seven percent of the sample was male, $42 \%$ was female, and $1 \%$ was transgender. The age range was 18 to 77 years, and the mean age was 34 . Among these participants, $89 \%$ identified themselves as heterosexual, $8 \%$ bisexual, and
$3 \%$ homosexual. In terms of race and ethnicity, $54 \%$ were Caucasians, 34\% were Asians, 5\% were African-American, $3 \%$ were Latino, and $4 \%$ indicated "other" (such as mixed or biracial). When asked about their level of education, $9 \%$ of the participants indicated they had a high school diploma or less, $22 \%$ had some college with no degree, $50 \%$ had 2-year or 4-year degrees, and $19 \%$ had a graduate degree.

\section{Measures}

\section{Pornography Usage Measure (PUM)}

The Pornography Usage Measure (PUM) is a set of items that evaluate how often an individual uses pornographic media of various formats. We developed this measure by adopting items that had been rated as pornographic from a previous study. In this previous study, participants were presented with a variety of items describing different types of sexual media from texts to videos or photographs with different levels of explicitness and asked to rate whether they were pornographic (Busby et al., 2017). The items were adapted for the current study by changing the response scale to ask about usage rather than perceptions. The PUM consists of 20 items (see "Appendix 1" for details). Participants were asked to read the list of items and indicate on a 6-point scale about how often in the last 12 months they had viewed this sexual content $(1=$ never to $6=$ every day or almost every day).

\section{Pornography Perception Measure}

While the main purpose of this study was to develop a scale that measured the usage and consumption of pornography, for statistical evaluation purposes and primarily to help us develop a shorter version of the scale, we also asked the participants to provide information regarding which materials they considered or perceived to be pornographic as was done in a previous study (Busby et al., 2017). For the pornography perception measurement, the participants were also presented the same list of 20 items as listed in "Appendix 1," but instead of being asked how often they used these items, they were asked "Consider the statements below and indicate if you believe they describe what you would consider pornography." They then indicated on a 10-point scale how much they considered the items to be pornographic, with 1 being "definitely not pornography" and 10 being "definitely pornography."

\section{General Pornography Use}

In order to test concurrent validity with the PUM, we tested the correlation between PUM and two simple, general pornography usage questions. This allowed us to consider a type of criterion validity. These two questions were: (1) During the last 12 months, on how many days did you view a video 
showing a graphic sexual act or fully nude people? (2) During the last 12 months, on how many days did you view a picture showing a graphic sexual act or fully nude people? Participants were to select one of the options from a 6-point scale $(1=$ never to $6=$ almost every day $)$.

\section{Relationship Instability}

To answer the third research question of this study and evaluate predictive validity, we also tested the practical function of PUM by predicting relationship instability using PUM as a bi-factor independent variable. The reason we chose relationship instability is because the literature has documented in the past that pornography does influence relationship outcome variables (Poulsen, Busby, \& Galovan, 2013; Stack, Wasserman, \& Kern, 2004; Wright, Tokunaga, Kraus, \& Klann, 2017). The relationship instability measure consisted of the following questions: (1) How often have you thought your relationship (or marriage) might be in trouble? (2) How often have you and your partner discussed ending your relationship (or marriage)? (3) How often have you broken up or separated and then gotten back together? (Busby, Holman, \& Taniguchi, 2001). The participants rated their responses on a 5 -point scale: $1=$ never to $5=$ very often. The higher the score, the less stable an individual perceived his/her couple relationship to be. These items were adapted from earlier work by Booth, Johnson, and Edwards (1983). Previous studies have shown this scale to have test-retest reliability values between .78 and .86 , to be appropriately correlated with other relationship quality measures, and to be valid for use in cross-sectional and longitudinal research (Busby, Holman, \& Niehuis, 2009; Busby et al., 2001; Busby, Ivey, Harris, \& Ates, 2007). Using the current sample, the reliability of the relationship instability scale was .84 .

\section{Analyses}

\section{Evaluating Reliability, Concurrent Validity, and Construct Validity}

In order to evaluate the reliability of the PUM and these two types of validity, we first obtained the Cronbach's alpha reliability index for PUM. Then, for concurrent validity, we computed the mean score of PUM and conducted Pearson's zero order correlation analysis to test the relationship between the PUM mean score and the questions that asked about general pornography use.

Following reliability and concurrent validity analyses, we conducted factor analyses to evaluate construct validity. As mentioned earlier, in a previous study Busby et al. (2017) found that all of the items of perception regarding pornography not only loaded onto one main factor, but they simultaneously loaded onto a second factor. This meant that pornography was best understood as a multidimensional concept. Multidimensional is different than multifactorial as multidimensional means the same items create several factors, whereas multifactorial means different items make up each factor. In the Busby et al. study, whether study participants considered something to be pornographic or not was influenced by their personal belief of what pornography was as well as how sensitive they were to different levels of sexualization in the media. The previous study thus established a bi-factor structure in which all pornography items loaded onto two distinct factors at the same time (see Fig. 1). In this current study, we planned to test whether a bi-factor structure would still be the most appropriate way to model the pornography usage items in contrast to the perception items in the previous study. If the bi-factor structure was accurate for the PUM items, it would indicate that pornography usage (just like perception of pornography) was also a multidimensional concept. To test this in the current study, as shown also in Fig. 1, we constructed a bi-factor exploratory structural equation model (ESEM) and loaded all of the PUM items simultaneously onto two distinct factors.

\section{Identifying Items for a Shortened Scale}

After evaluating the reliability and validity of the constructs, we proceeded to identify items that could best capture the essence of the scale and could be used to create a shortened scale for researchers who may not wish to adopt a full 20 -item scale. To do so, we examined the descriptive and factor analysis information of these items, and we further constructed a bi-factor item response model. Item response models provided more information than what traditional descriptive and factor analyses could provide. We further plotted the individual item information surfaces from the information we obtained from the items response models, to help us examine the strength of each item.

\section{Testing Predictive Validity}

We evaluated predictive validity by creating a structural equation model in which we treated PUM as a bi-factor independent variable. In this model, we tested whether both factors would significantly predict relationship instability as an outcome variable.

\section{Results}

\section{Reliability, Concurrent Validity, and Factor Analyses}

We expected the reliability of this scale to be lower than attitudinal scales as each item represents different types of sexual media and sexual explicitness so an individual might 

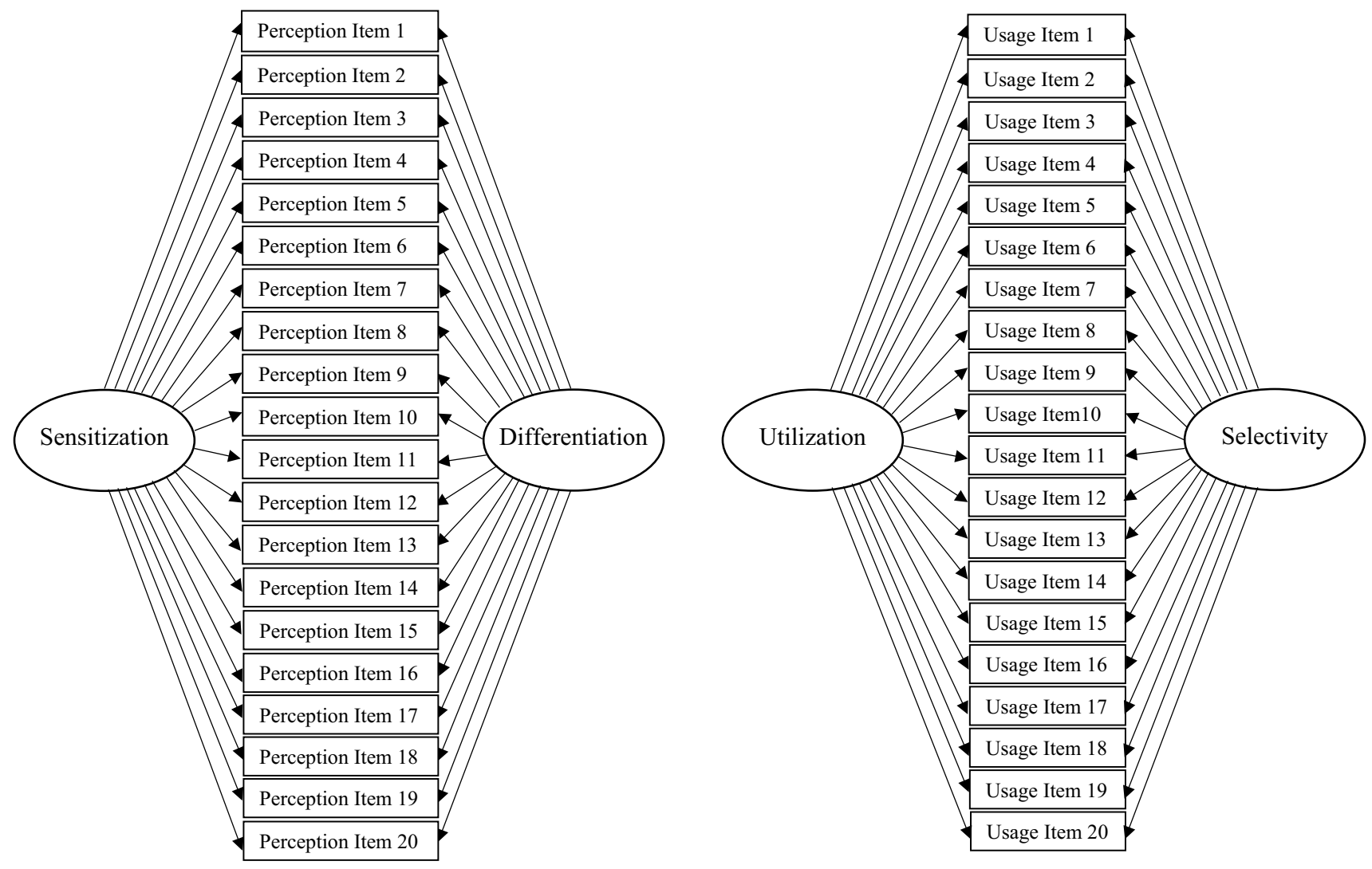

Fig. 1 Bi-factor structures of the Pornography Usage Measure and the pornography perception items. Figure on the left was the proposed and tested bi-factor model in a previous study. Figure on the right was the bi-factor structure tested in this current study

view one type of media and not the other. Results of reliability analysis showed that Cronbach's alpha was .71, and that removing any item from the scale would not have increased the reliability dramatically, indicating the items worked reasonably well together as a scale.

To explore concurrent validity, we conducted a correlation analyses between the total scale score and the two general pornography questions for video and pictures. The results showed that PUM and the general pornographic video usage item were significant, $r=.52, p<.01, d f=1637$. The correlation between PUM mean score and the general pornographic picture usage item was also significant, $r=.55$, $p<.01, d f=1637$.

To evaluate construct validity, we conducted a bi-factor factor analysis (ESEM). The factor analysis showed that a bi-factor structure suited the PUM items well, $\chi^{2}=1607.16$ with $136 d f, p<.01, \mathrm{CFI}=.98$, TLI $=.97$, $\mathrm{RMSEA}=.08$, $90 \%$ C.I. $=.08-.09$. Table 1 lists the individual item factor loadings as well as the R-square values of each item, and Fig. 1 shows the bi-factor model structure. As mentioned previously, the bi-factor model in this paper was built based on findings from previous studies on pornography perception items (Busby et al., 2017). In the previous study, the first factor of the pornography perception model was named sensitization, which captured the participants' tendency to rate all items as more or less pornographic based on how sensitized and/or sensitive they were toward sexualized media. The second factor of the pornography perception items was named differentiation, which referred to the participants' propensity to distinguish different levels of sexualized media (such as rating one item as highly pornographic or another as less). In the current study, since we were studying pornography usage instead of perceptions, we gave these factors different names: utilization and selectivity. Even though the names were different, the factor loading patterns were very similar and we believed that the factors represented similar patterns of how study participants perceived and used the pornographic media. utilization therefore referred to the extent to which the study participants consumed sexualized media, which we believed also reflected the participants' level of sensitization. It is likely that when participants were more or less sensitized to pornography and rated all items to be more or less pornographic, they were also more prone to use or not use these media in general. Meanwhile, the second factor, selectivity, indicated the participants' selective exposure to more sexualized media. We believed that as participants differentiated between items that they considered to contain different levels of sexuality, they were also selective 
Table 1 Bi-factor exploratory structural equation models for the Pornography Usage Measure

\begin{tabular}{llll}
\hline Pornography Usage Measure items & $\begin{array}{l}\text { Factor 1 (utili- } \\
\text { zation) }\end{array}$ & $\begin{array}{l}\text { Factor 2 (selec- } \\
\text { tivity) }\end{array}$ & $R^{2}$ \\
\hline 1. Written example of couple kissing/touching each other & $.67^{* *}$ & $-.33^{* *}$ & .56 \\
2. Written example of couple engaging in foreplay/sex & $.71^{* *}$ & $-.23^{* *}$ & .56 \\
3. Video of two men having sexual intercourse & $.72^{* *}$ & $-.11^{* *}$ & .53 \\
4. Swimsuit issue of a magazine & $.79^{* *}$ & $-.22^{* *}$ & .68 \\
5. Television program of filming of a swimsuit edition & $.80^{* *}$ & $-.36^{* *}$ & .76 \\
6. Image of a woman posing with underwear on & $.73^{* *}$ & -.00 & .54 \\
7. Image of a woman exposed breasts and panties on & $.78^{* *}$ & $.09^{*}$ & .61 \\
8. Image of a woman posing without any clothes & $.76^{* *}$ & $.21^{* *}$ & .62 \\
9. Image of a man posing with only underwear on & $.74^{* *}$ & $-.31^{* *}$ & .64 \\
10. Image of a man posing without any clothing & $.78^{* *}$ & $-.17^{* *}$ & .64 \\
11. Video of consensual sex; women's breasts shown & $.79^{* *}$ & $.13^{* *}$ & .64 \\
12. Picture of couple having sex; women's breasts shown & $.83^{* *}$ & $.11^{* *}$ & .70 \\
13. Image of a man's penis penetrating a woman & $.71^{* *}$ & $.52^{* *}$ & .77 \\
14. Video showing two naked women/men kissing & $.78^{* *}$ & $.38^{* *}$ & .75 \\
15. Video of two naked women/men stimulating each other & $.75^{* *}$ & $.42^{* *}$ & .73 \\
16. Video of a woman or man alone masturbating & $.75^{* *}$ & $.37^{* *}$ & .70 \\
17. Novel that includes graphic depiction of sex & $.77^{* *}$ & $-.31^{* *}$ & .69 \\
18. Television show of strippers and blurred nudity & $.84^{* *}$ & $-.38^{* *}$ & .85 \\
19. Video that graphically depicts three-way sex & $.75^{* *}$ & $.37^{* *}$ & .71 \\
20. Hollywood film including graphic sexual encounter & $.72^{* *}$ & $-.17^{* *}$ & .55 \\
\hline
\end{tabular}

$\mathrm{N}=1639 . * \mathrm{p}<.01, * * \mathrm{p}<.001 . \chi^{2}=1607.16(\mathrm{df}=136, \mathrm{p}<.01), \mathrm{CFI}=.98, \mathrm{TLI}=.97, \mathrm{RMSEA}=.08,90 \%$ C.I. $=.08-.09$. Error correlations were applied among some of the items. The item descriptions are shorted from the full versions. For the full item descriptions, see "Appendix 1" in terms of whether or how they would view the particular types of sexualized media. For the utilization factor, all of the items had strong factor loadings, ranging from .67 to .84 and were statistically significant, $p<.001$. For the selectivity factor, the item loadings ranged from strong positive $(r=.52$, $p<.001)$ to strong negative $(r=-.38, p<.001)$. Particularly, Items 13-16, and 19 grouped together with strong positive loadings, Items $1,5,9,17$, and 18 grouped together with strong negative loadings, with the rest of the items spreading across the spectrum.

Concluding from the reliability, correlation, and bi-factor exploratory structural equation modeling, all items in the PUM appeared to be effective in measuring the latent traits, although some items had stronger loadings than others.

\section{Identifying Items for a Shortened Scale}

After all items in the PUM were analyzed and examined in the bi-factor model, we felt confident that the full scale captured a broad and well-defined picture of pornography usage, and we proceeded to identify items that may best capture the essence of pornography in hopes of creating a shortened version of the instrument. In order to create a shortened scale, we compared the study participants' responses on both the Pornography Usage Measure and pornography perception measures to decide which items not only were considered pornographic, but also were commonly used. An item would not be particularly useful if, although everyone agreed it was pornographic, almost nobody looked at this type of sexual media. The analyses we conducted using these measures included basic descriptive analyses (such as mean and SD) as well as bi-factor CFA models. We selected items to be included in the shortened Pornography Usage Measure only when they met the following criteria: (1) the item needed to be perceived as relatively pornographic (i.e., above 7 on the perception scale), and was also used frequently enough (i.e., above 2.25 on the usage scale). In other words, for descriptive statistics, the items selected needed to have larger means for both the perception and usage measures; (2) the items in the shortened Pornography Usage Measure needed to represent the latent concept well, and were not repetitive. In other words, in the CFA models, the PUM items needed to have higher R-square values so that they accounted for more variance in the model, and also did not repeatedly represent the same types of media; (3) the items had stronger item information surfaces when evaluated with a common Item Response Theory Statistical Program, flexMIRT (Houts \& Cai, 2016). After identifying items that we deemed most appropriate to be included in the shortened scale, we evaluated the short scale by examining its Cronbach's alpha reliability and its correlation with the long scale. 
The first analysis we conducted to evaluate individual items for developing a shortened scale was an item response model with flexMIRT. We estimated a bi-factor two-parameter graded response item model. The model was successfully executed, with all items loading on both the first factor ("utilization") and the second factor ("selectivity"). The estimated item factor loadings were fairly similar to those obtained from the bi-factor ESEM results reported earlier. As mentioned previously, we created item information surfaces. These surfaces illustrate graphically how well an individual item covers the information available for the two dimensions of utilization and selectivity. A surface that shows more information is covered by the item is usually less flat and spreads across the two dimensions like Item 15 , though this is difficult to see clearly in a two-dimensional figure because these are three-dimensional curves and ideally the researcher is able to look at the figure as it is rotated dynamically to see all sides of the information curve.

A simplified version of all of the 3-D item information surfaces is shown in Fig. 2. Note that each of these surfaces was facing different directions. Excel was capable of interactively rotating the surfaces, so we were able to visualize the different amount of item information that was covered in the different regions of the trait space as we rotated each of them within the program. However, Fig. 2 does show that even with different angles, certain items did peak higher. This means they contained more information than other items and were more discriminating. We utilized this information along with the data on usage and perception means to select items for the shortened version. For example, Items 5, 14-16, and 18-19 peaked higher than the other items (with Item 15 peaking the highest) and were strongly informative with respect to both utilization and selectivity. These items contained the most information. Despite some variation, the other items were each somewhat less informative and provided information primarily about the utilization dimension rather than about selectivity.

Additional criteria for creating a shortened scale other than the IRT analyses were: (1) Did the participants consider the items to be relatively pornographic? (2) Were usage rates relatively high? (3) Did items have strong loadings onto the latent traits and did they account for more variance in the ESEM? and (4) Were items not repetitive with other items in the scale? Tables 1, 2, and Fig. 2 show information that helped us make these decisions.

First, the mean of each pornography usage item and each pornography perception item (Table 2) helped us decide whether an item was considered pornographic and also frequently used. For example, when comparing Items 1, 10 , and 13, Item 1 received relatively low ratings on both the perception and usage scales, while Item 10 received higher ratings on the perception scale yet low ratings on the usage scale. Item 13 was rated relatively high for both perception and usage scales. This indicated that participants did not consider Item 1 to be very pornographic nor was this item used as often as others, while Item 10 was considered highly pornographic yet still not frequently used, and that Item 13 was considered to be both fairly pornographic and was used more often than the other two items. Item 13, in this case, would be selected to be part of the shortened scale.

Besides comparing the mean scores, we also compared the item information surfaces as well as factor loadings and $\mathrm{R}$-square information to identify preferred items. Using results from the item response model, we kept items that had rich information contained in the information surfaces (Fig. 2). After reviewing results from the ESEM, we kept items that loaded well onto the factors and also had higher R-square values (Table 1). Finally, we removed items that were repetitive or redundant. For example, Items 14 and 15 both had high mean scores on perception and usage scales, they both had very rich item information in the item response model, and they both had ideal factor loadings as well as R-square values in the ESEM. However, they were also highly correlated and appeared to be repetitive. After examining both of the items, we chose to retain Item 15 instead of 14.

For the final shortened scale, we retained Items 8 , 11-13, 15-16, and 19. These items were examined again using bi-factor ESEM, and the model statistics suggested an adequate fit to the data, $\chi^{2}=147.52(d f=8, p<.01)$, $\mathrm{CFI}=.99, \mathrm{TLI}=.99, \mathrm{RMSEA}=.10,90 \%$ C.I. $=.09-.12$.

\section{Predictive Validity}

Finally, we estimated a structural equation model predicting relationship instability with PUM as a bi-factor independent variable. Figure 3 depicts the structure and the output of this model. The model fit information is as follows: $\chi^{2}=1192.69(d f=194, p<.01), \mathrm{CFI}=.97, \mathrm{TLI}=.96$, RMSEA $=.06,90 \%$ C.I. $=.05-.06$. Both the utilization factor and the selectivity factor significantly and positively predicted an individual's relationship instability. To be more specific, when participants scored higher on both the utilization factor and the selectivity factor of PUM, they also demonstrated lower stability in their romantic relationships. As mentioned previously, utilization represented the extent that the participants used pornographic materials, while selectivity represented the participants' selective exposure to more sexualized media. Therefore, when participants manifested heavier utilization of pornography, they also demonstrated more relationship instability. Likewise, when participants showed a pattern of selecting more sexualized media, they had more relationship instability. 

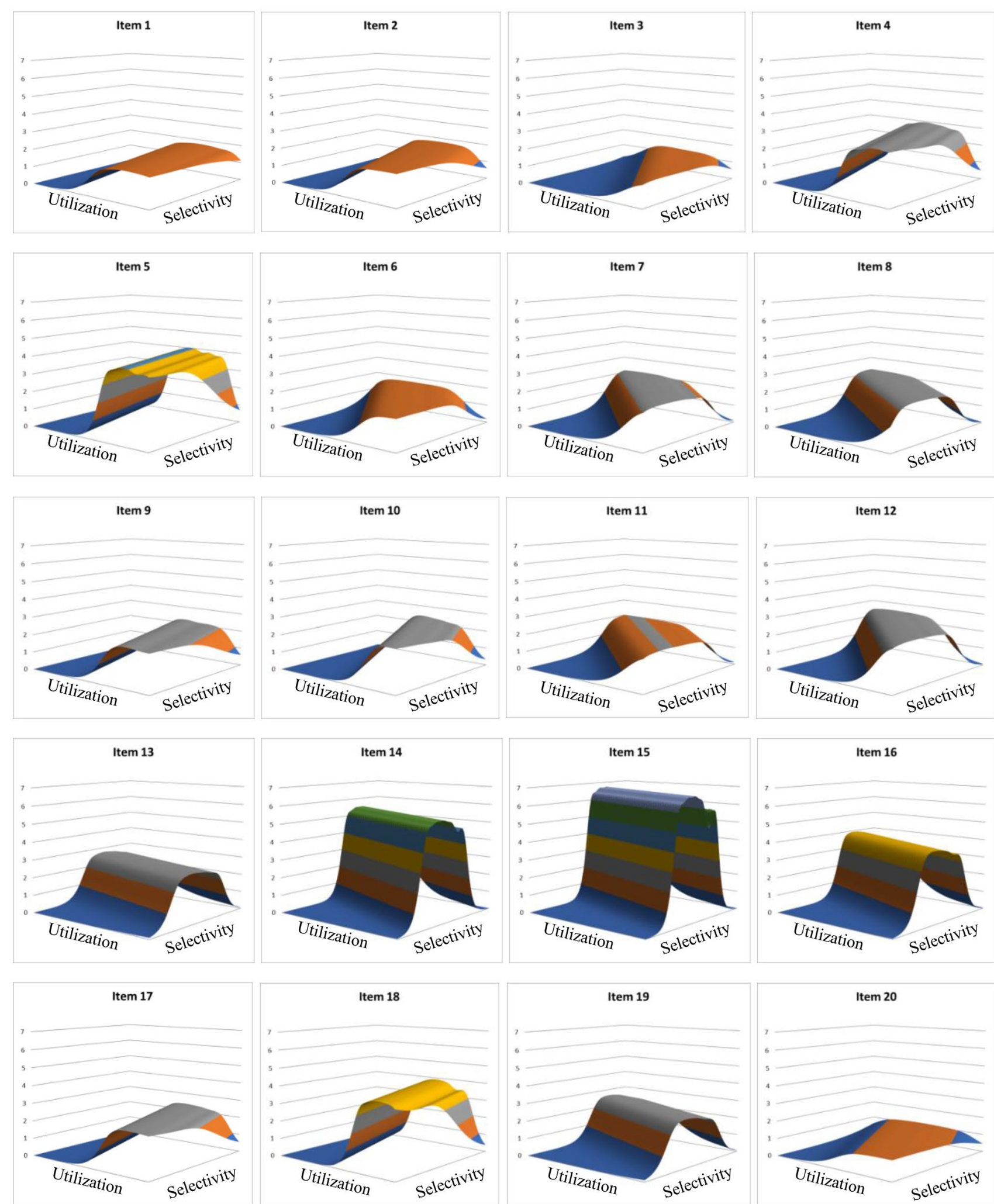

Fig. 2 Item information surfaces for individual pornography usage items. Note The $\mathrm{z}$ axis ranged from 0 to 7 . All surfaces were rotated to $\mathrm{X}=40^{\circ}$ and $\mathrm{Y}=10^{\circ}$ in Excel for consistency 
Table 2 Mean and standard deviation of the pornography perception and usage scales
Fig. 3 Predicting relationship instability using Pornography Usage Measure as a bi-factor independent variable. Note $\mathrm{N}=1639$. ** $\mathrm{p}<.001$. $\chi^{2}=1192.69(\mathrm{df}=194$, $\mathrm{p}<.01), \mathrm{CFI}=.97, \mathrm{TLI}=.96$, RMSEA $=.06,90 \%$ C.I. $=.05-$ .06

\begin{tabular}{|c|c|c|c|c|}
\hline \multirow[t]{2}{*}{ Items (shortened descriptions) } & \multicolumn{2}{|c|}{ Usage items } & \multicolumn{2}{|c|}{ Perception items } \\
\hline & M & SD & $\mathrm{M}$ & $\mathrm{SD}$ \\
\hline 1. Written example of couple kissing/touching each other & 1.94 & 1.24 & 4.12 & 2.67 \\
\hline 2. Written example of couple engaging in foreplay/sex & 1.95 & 1.25 & 6.05 & 2.75 \\
\hline 3. Video of two men having sexual intercourse & 1.70 & 1.23 & 8.62 & 2.43 \\
\hline 4. Swimsuit issue of a magazine & 1.90 & 1.20 & 4.22 & 2.79 \\
\hline 5. Television program of filming of a swimsuit edition & 1.78 & 1.18 & 3.79 & 2.70 \\
\hline 6. Image of a woman posing with underwear on & 2.26 & 1.33 & 4.37 & 2.69 \\
\hline 7. Image of a woman exposed breasts and panties on & 2.30 & 1.39 & 6.13 & 2.67 \\
\hline 8. Image of a woman posing without any clothes & 2.40 & 1.47 & 7.13 & 2.66 \\
\hline 9. Image of a man posing with only underwear on & 1.89 & 1.30 & 4.81 & 2.84 \\
\hline 10. Image of a man posing without any clothing & 1.81 & 1.28 & 6.95 & 2.79 \\
\hline 11. Video of consensual sex; women's breasts shown & 2.33 & 1.38 & 7.40 & 2.44 \\
\hline 12. Picture of couple having sex; women's breasts shown & 2.25 & 1.38 & 7.40 & 2.50 \\
\hline 13. Image of a man's penis penetrating a woman & 2.69 & 1.58 & 8.87 & 2.02 \\
\hline 14. Video showing two naked women/men kissing & 2.44 & 1.51 & 7.52 & 2.65 \\
\hline 15. Video of two naked women/men stimulating each other & 2.44 & 1.51 & 8.49 & 2.23 \\
\hline 16. Video of a woman or man alone masturbating & 2.32 & 1.50 & 8.47 & 2.25 \\
\hline 17. Novel that includes graphic depiction of sex & 1.90 & 1.29 & 6.18 & 2.86 \\
\hline 18. Television show of strippers and blurred nudity & 1.75 & 1.22 & 5.26 & 2.87 \\
\hline 19. Video that graphically depicts three-way sex & 2.36 & 1.54 & 8.70 & 2.14 \\
\hline 20. Hollywood film including graphic sexual encounter & 2.35 & 1.35 & 6.07 & 2.85 \\
\hline
\end{tabular}

$\mathrm{N}=1639$. The absolute range for usage items is 1 to 6 , and the absolute range for perception items is 1 to 10. These descriptions are shortened. For the detailed item descriptions, see "Appendix 1"

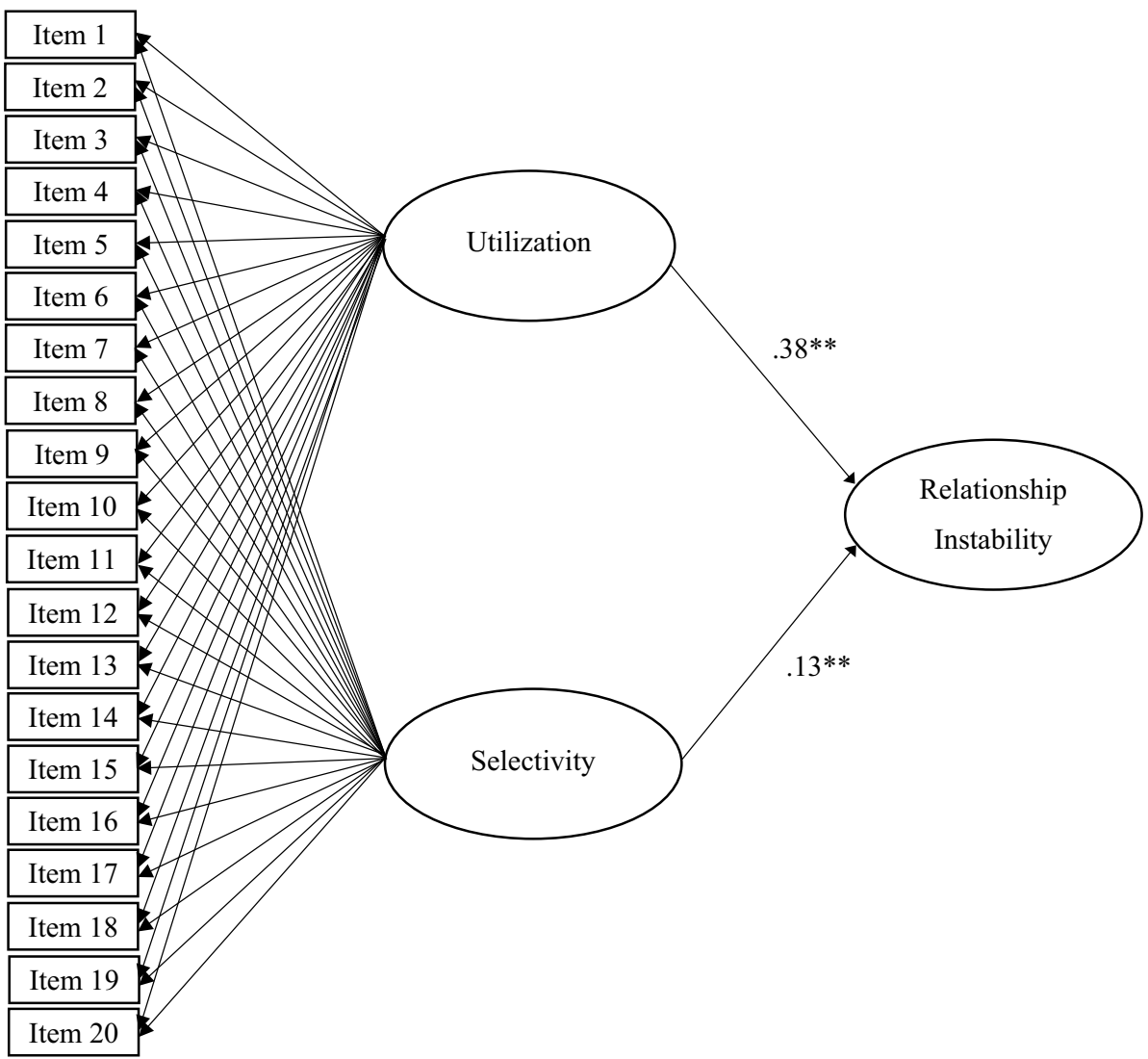




\section{Discussion}

Pornography use is becoming more common, yet there is still much to be learned about its influence on how people view sexuality and behave sexually as well as how it influences relationships (Price et al., 2016). There is considerable controversy over whether the influence of pornography is positive or negative, short or long term, significant or minor (Grubbs \& Perry, 2019; Leonhardt, Spencer, Butler, $\&$ Theobald, 2019; Ley, Prause, \& Finn, 2014). Before these important questions can be answered, it is important to measure pornography usage with reliable and valid measures so that comparisons across groups, studies, and time can be made. We believe the PUM is an important step forward in creating such a measure and that it could be coupled with other new measures evaluating attitudes and feelings about pornography ((Bôthe et al., 2018; Grubbs et al., 2010; Hald \& Štulhofer, 2016) to develop sophisticated research studies.

In this study, we addressed four research questions. We found evidence supporting each of these research questions in that we were able to create a reliable measure of pornography that had initial findings supportive of concurrent, construct, and predictive validity. The PUM measure is a multidimensional instrument that evaluates both the utilization and selectivity factors. In addition, we were able to develop a short seven-item multidimensional version of the PUM that should be useful for scholars and applied professionals who have more limited amounts of time and space to devote to the assessment of pornography usage. This shortened version also has the advantage of tapping into items that show the widest area of information coverage, are viewed as being highly pornographic, and are more likely to be viewed than some of the items on the longer measure. Many scholars will not have space to add 20 items to their study on pornography unless pornography is the primary variable of interest. When it is not the primary variable of interest, we feel confident in recommending the short seven item measure. In instances where pornography usage is the primary variable of interest, it may be beneficial to use the longer version and have additional items to increase the chance that unique usage patterns for individuals will be detected and measurement error will be reduced.

\section{Limitations and Future Research}

As with any initial study of a new instrument, there were limitations to this study. While two separate international samples and two studies were used to discover what types of media were considered pornographic and one sample was used to evaluate usage rates, neither sample used in the development of this instrument was representative of a particular country. Since pornography usage has moved to largely Internet-based media (Wright, 2013), it is a worldwide phenomenon and it is important to produce instruments that can be used across many countries. Nevertheless, it would be crucial to enhance the validity information on the PUM by utilizing different samples from English-speaking countries that are more representative of specific countries and then translating the instrument into other languages so that cross-cultural research could be conducted. It may be that both the perception of what is pornographic and usage rates are so distinct between different countries that different versions have to be developed for different countries.

It is possible to consider the time frame we used on the PUM "during the last 12 months" as a limitation straining the memory of participants. There are limitations to any time frame that is used requiring people to remember the past. While shorter time frames may be more accurate, with a behavior that can be associated with feelings of guilt or desires to stop, there is likely to be variations in usage that may include engaging and disengaging in the behavior as some researchers have found with pornography (Perry \& Schleifer, 2018; Willoughby, Young-Peterson, \& Leonhardt, 2018). This means that if we asked about a shorter time frame such as the last few months individuals may report artificially low or high usage because they have recently binged or tried to reduce usage of pornography. We believe the 12-month time frame has advantages of producing a measurement across time that might not be as prone to artificial variations. In the end, the best time frame to use for such questions is an empirical question that can be evaluated by future research.

Another potential limitation is that the PUM did not cover all types of pornography such as child pornography, fetishes, and other variations. This was a deliberate choice as we were attempting to measure "common types" of pornographic material and to avoid reporting requirements associated with questions on child pornography, and unduly distressing individuals by asking them to read depictions that they might find more offensive than the ones we already wrote. Our purpose was not to cover all the possible content, but to cover content most people considered pornographic and viewed on occasion. Still, scholars interested in different types of sexual media or more extreme forms of pornography would need to add modules and test their reliability and validity with samples that were more likely to use these different types of materials as more sexually explicit items in the PUM were rarely viewed by most individuals.

Finally, all of the samples used for the development of the PUM were cross-sectional. To improve the validity information about the PUM, longitudinal samples evaluating usage rates across time with different predictors would be important. 
Even with these shortcomings, we believe the PUM is an improvement over the existing measures of pornography. When participants answer the questions on the PUM, it is clear that they are reporting on whether they have seen media that is similar to specific scenarios that include common sexual media most people would consider to be pornographic. This means that we are not left to rely primarily on their internal judgments of what is or is not pornographic, which is a serious problem influencing the validity of most measures. In fact, we never used the term "pornography" or any of its derivatives in the instrument. Additionally, having a long and short version of the instrument is advantageous for scholars and practitioners working within different contexts with limited resources. Finally, the multidimensional nature of this instrument lends itself to unique research opportunities that may be able to show differential influences of the two dimensions of utilization and selectivity. For scholars and practitioners to use an instrument that is multidimensional where several factors are produced by the very same items, it is necessary to create factors scores with a statistical program because it is not possible to just use a total scale score to evaluate both utilization and selectivity. Obtaining factor scores is a very straightforward process in most statistics programs, but the program has to be able to create multidimensional factor models. Mplus is one of the best programs for such a model and the syntax for creating these factor scores is in "Appendix 2."

\section{Compliance with Ethical Standards}

Conflict of interest There were no conflicts of interest for any of the authors of this manuscript.

Ethical Approval All procedures performed in studies involving human participants were in accordance with the ethical standards of the institutional and/or national research committee and with the 1964 Helsinki Declaration and its later amendments or comparable ethical standards.

Informed Consent Informed consent was obtained from all individual participants included in the study.

\section{Appendix 1: Pornography Usage Measure (PUM)}

Please indicate how often in the last 12 months you have viewed or used the following sexual content. $(1=$ Never, $2=$ Once a month or less, $3=2$ or 3 days a month, $4=1$ or 2 days a week, $5=3$ to 5 days a week, $6=$ Every day or almost every day)
1. A detailed description in writing of a couple passionately kissing and touching each other's clothed bodies and describing their arousal.

2. A detailed description in writing of a couple engaging in foreplay and sex that includes mention of specific sexual body parts that are touched and aroused as sexual acts are performed.

3. A video of two men having sexual intercourse with each other.

4. A swimsuit issue of a magazine showing models in skimpy swimsuits or strategically covered topless views in a variety of provocative poses.

5. A television program showing the filming of a swimsuit edition of a magazine that shows models being filmed in a variety of provocative poses but no full nudity of breasts or genitalia.

6. An image of a woman alone posing in a suggestive way with underwear on.

7. An image of a woman alone posing in a suggestive way with exposed breasts and panties on.

8. An image of a woman alone posing in a suggestive way without any clothes on.

9. An image of a man alone posing in a suggestive way with only underwear on.

10. An image of a man alone posing in a suggestive way without any clothing on.

11. A short video depicting a couple having consensual sex. The women's breasts are shown but neither partner's genitalia are shown.

12. A picture of a couple having sex, the women's breasts are shown but neither partner's genitalia are shown.

13. An image of a heterosexual couple having sex which shows the man's penis penetrating the woman.

14. A video showing two naked women or men kissing each other.

15. A video showing two naked women or men manually stimulating each other.

16. A video of a woman or man alone masturbating.

17. A novel that includes one graphic depiction of sexual intercourse.

18. A television show focused on strippers that includes multiple instances of blurred nudity.

19. A video that graphically depicts a three-way sexual encounter.

20. A major Hollywood film or movie that includes one graphic sexual encounter.

Note: Items in bold are items suggested for the shortened PUM. 


\section{Appendix 2: MPlus Syntax for Obtaining Factor Scores for the Utilization and Selectivity Factors}

Title: PUM Scale

Data:

File is (Put in File name with data).

Variable:

Names are U1 U2 U3 U4 U5 U6 U7 U8 U9 U10

U11 U12 U13 U14 U15 U16 U17 U18 U19 U20 U21

$\mathrm{U} 22$;

Missing are all (-99);

CATEGORICAL ARE ALL;

USEVARIABLES ARE U1 U2 U3 U5 U6 U7 U8 U9

U10

U11 U12 U14 U15 U16 U17 U18 U19 U20 U21 U22;

ANALYSIS: ROTATION IS BI-GEOMIN (ORTHOGONAL);

MODEL:

f1-f2 by U1 U2 U3 U5 U6 U7 U8 U9 U10

U11 U12 U14 U15 U16 U17 U18 U19 U20 U21 U22(*1);

F1-F2 WITHF1-F2@0;

OUTPUT:

STDYX;

MODINDICES (ALL 0);

TECH4;

SAVEDATA:

File is Study.csv;

SAVE $=$ FSCORES;

\section{References}

Booth, A., Johnson, D. R., \& Edwards, J. N. (1983). Measuring marital instability. Journal of Marriage and the Family, 45, 387-394.

Bőthe, B., Tóth-Király, I., Zsila, Á., Griffiths, M., Demetrovics, Z., \& Orosz, G. (2018). The development of the Problematic Pornography Consumption Scale (PPPCS). Journal of Sex Research, 55, 395-406.

Busby, D. M., Chiu, H.-C., Willoughby, B. J., \& Olsen, J. A. (2017). Evaluating the dimensionality of pornography. Archives of Sexual Behavior, 46, 1723-1731.

Busby, D. M., Holman, T. B., \& Niehuis, S. (2009). The association between partner- and self-enhancement and relationship quality outcomes. Journal of Marriage and the Family, 71, 449-464.

Busby, D. M., Holman, T. B., \& Taniguchi, N. (2001). RELATE: Relationship evaluation of the individual, family, cultural, and couple contexts. Family Relations, 50, 308-316.

Busby, D. M., Ivey, D. C., Harris, S. M., \& Ates, C. (2007). Selfdirected, therapist-directed, and assessment-based interventions for premarital couples. Family Relations, 56, 279-290.

Butler, M. H., Pereyra, S. A., Draper, T. W., Leonhardt, N. D., \& Skinner, K. B. (2017). Pornography use and loneliness: A bidirectional recursive model and pilot investigation. Journal of Sex and Marital Therapy, 44, 127-137. https://doi.org/10.1080/00926 23X.2017.1321601.
Daneback, K., Traeen, B., \& Mansson, S. (2009). Use of pornography in a random sample of Norwegian heterosexual couples. Archives of Sexual Behavior, 38, 746-753. https://doi.org/10.1007/s1050 8-008-9314-4.

Fitzpatrick, A. R. (1983). The meaning of content validity. Applied Psychological Measurement, 7, 3-13. https://doi. org/10.1177/014662168300700102.

Grubbs, J. B., \& Perry, S. L. (2019). Moral incongruence and pornography use: A critical review and integration. Journal of Sex Research, 56, 29-37.

Grubbs, J. B., Sessoms, J., Wheeler, D. M., \& Volk, F. (2010). The Cyber-Pornography Use Inventory: The development of a new assessment instrument. Sexual Addiction and Compulsivity, 17, 1050126.

Grubbs, J. B., Volk, F., Exline, J. L., \& Pargament, K. I. (2015). Internet pornography use: Perceived addiction, psychological distress, and the validation of a brief measure. Journal of Sex and Marital Therapy, 41, 83-106.

Hald, G. M., Seaman, C., \& Linz, D. (2014). Sexuality and pornography. In D. L. Tolman \& L. M. Diamond (Eds.), APA handbook of sexuality and psychology (Vol. 2, pp. 3-36). Washington, DC: American Psychological Association.

Hald, G. M., \& Štulhofer, A. (2016). What types of pornography do people us and do they cluster? Assessing types and categories of pornography consumption in a large-scale online sample. Journal of Sex Research, 53, 849-856.

Hartig, J., \& Höhler, J. (2008). Representation of competencies in multidimensional IRT models with within-item and betweenitem multidimensionality. Journal of Psychology, 216, 89-101.

Houts, C. R., \& Cai, L. (2016). FlexMIRT user's manual version 3.5: Flexible multilevel multidimensional item analysis and test scoring. Chapel Hill, NC: Vector Psychometric Group.

Kingston, N. M., Scheuring, S. T., \& Kramer, L. B. (2013). Test development strategies. In K. F. Geisinger (Ed.), APA handbook of testing and assessment in psychology (Vol. 1, pp. 165-184). Washington, DC: American Psychological Association.

Leonhardt, N. D., Spencer, T. J., Butler, M. B., \& Theobald, A. C. (2019). An organizational framework for sexual media's influence on short-term versus long-term sexual quality. Archives of Sexual Behavior, 48, 2233-2249.

Ley, D., Prause, N., \& Finn, P. (2014). The emperor has no clothes: A review of the 'pornography addiction' model. Current Sexual Health Reports, 6, 94-105.

Malamuth, N. M., Addison, T., \& Koss, M. (2000). Pornography and sexual aggression: Are there reliable effects and can we understand them? Annual Review of Sex Research, 11, 26-91. https:// doi.org/10.1080/10532528.2000.10559784.

Perry, S. L., \& Schleifer, C. (2018). Till porn do us part? A longitudinal examination of pornography use and divorce. Journal of Sex Research, 55, 284-296.

Poulsen, F. O., Busby, D. M., \& Galovan, A. M. (2013). Pornography use: Who uses it and how it is associated with couple outcomes. Journal of Sex Research, 50, 72-83.

Price, J., Patterson, R., Regnerus, M., \& Walley, J. (2016). How much more XXX is generation X consuming? Evidence of changing attitudes and behaviors related to pornography since 1973. Journal of Sex Research, 53, 12-20.

Rasmussen, K. R., Grubbs, J. B., Pargament, K. I., \& Exline, J. J. (2018). Social desirability bias in pornography-related selfreports: The role of religion. Journal of Sex Research, 55, 381-394.

Sireci, S. G., \& Sukin, T. (2013). Test validity. In K. F. Geisinger (Ed.), APA handbook of testing and assessment in psychology (Vol. 1, pp. 61-84). Washington, DC: American Psychological Association.

Stack, S., Wasserman, I., \& Kern, R. (2004). Adult social bonds and use of Internet pornography. Social Science Quarterly, 85, 75-88. 
Willoughby, B. J., \& Busby, D. M. (2016). In the eye of the beholder: Exploring variations in the perceptions of pornography. Journal of Sex Research, 53, 678-688.

Willoughby, B. J., Young-Peterson, B., \& Leonhardt, N. D. (2018). Exploring trajectories of pornography use through adolescence and emerging adulthood. Journal of Sex Research, 55, 297-309.

Wright, P. J. (2013). U.S. males and pornography, 1973-2010: Consumption, predictors, correlates. Journal of Sex Research, 50, $60-71$.
Wright, P. J., Tokunaga, R. S., Kraus, A., \& Klann, E. (2017). Pornography consumption and satisfaction: A meta-analysis. Human Communication Research, 43, 315-343.

Publisher's Note Springer Nature remains neutral with regard to jurisdictional claims in published maps and institutional affiliations. 